\title{
Non-compliance of hand hygiene using covert and overt methodology among healthcare workers at a tertiary care hospital in Saudi Arabia
}

\author{
A El-Saed*, S Noushad, HH Balkhy \\ From 3rd International Conference on Prevention and Infection Control (ICPIC 2015) \\ Geneva, Switzerland. 16-19 June 2015
}

\begin{abstract}
Introduction
Hand hygiene $(\mathrm{HH})$ is a core element in preventing healthcare-associated infections and the spread of antimicrobial resistance. Although the benefits of $\mathrm{HH}$ are non-controversial, the $\mathrm{HH}$ compliance is still suboptimal. The degree of $\mathrm{HH}$ compliance is thought to be affected by the awareness of healthcare workers (HCWs) of being monitored.
\end{abstract}

\section{Objectives}

To estimate the frequency of $\mathrm{HH}$ non-compliance using covert methodology and to compare such frequencies to corresponding traditional $\mathrm{HH}$ surveillance from the same locations and time periods.

\section{Methods}

A cross-sectional study design was conducted at King Abdulaziz Medical City, Riyadh, Saudi Arabia, between October 2012 and July 2013. Non-compliance was defined as missing both hand rubbing (with alcoholbased formulation) and hand washing (with soap and water) during one of the WHO five-moment $\mathrm{HH}$ indications (opportunities). Observations were conducted quietly without attempts to promote $\mathrm{HH}$ compliance or provide performance feedback to HCWs.

\section{Results}

A total of 6580 opportunities were observed among different professional categories in 28 hospital locations. The overall non-compliance from the current study was $54.1 \%$ compared with $12.9 \%$ in traditional HH surveillance $(\mathrm{p}<0.001)$. The same significant trend was replicated by professional category $(53.1 \%$ vs. $10.2 \%$ in nurses, $53.8 \%$ vs. $19.6 \%$ in physicians, and $57.1 \%$ vs. $13.2 \%$ in other HCWs), service locations (54.3\% vs. $8.6 \%$ in intensive care and step-down units, $51.8 \%$ vs. $14.1 \%$ in inpatient wards, and $58.2 \%$ vs. $16.0 \%$ in emergency locations), and $\mathrm{HH}$ indications $(47.5 \%$ vs. $10.5 \%$ in precontact with patients, $60.1 \%$ vs. $10.5 \%$ in post-contact with patients, $57.3 \%$ vs. $2.7 \%$ in post-exposure to body fluids, $68.5 \%$ vs. $5.6 \%$ in before aseptic tasks, and $49.8 \%$ vs. $17.5 \%$ in post-contact with patient surroundings).

\section{Conclusion}

Major differences in non-compliance were detected during covert and overt $\mathrm{HH}$ monitoring irrespective of hospital location, professional category, and indications. Overlapping methods of auditing and frequent change of data collectors may reduce the underestimation of non-compliance.

\section{Disclosure of interest}

None declared.

Published: 16 June 2015

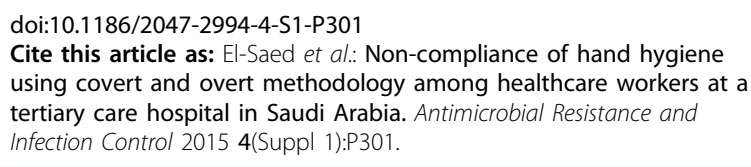

